\title{
MAGNETIC ANOMALY PATTERN IN THE WESTERN MEDITERRANEAN
}

\author{
R. BAYER and J.L. LE MOUEL \\ Institut de Physique du Globe, Paris, France \\ and \\ X. LE PICHON * \\ Centre Océanologique de Bretagne, Brest, France \\ Received 7 November 1972 \\ Revised version received 25 January 1973
}

\begin{abstract}
- A survey of the southern part of the Balearic Basin was flown in 1971 at a height of $600 \mathrm{~m}$. The results of a survey of the northern part, flown at a height of $3000 \mathrm{~m}$, which was previously published, have been downward continued to a height of $600 \mathrm{~m}$. The resulting composite map shows well defined low amplitude (100 gammas) magnetic lineations of the Vine et Matthews' type offset by fracture zones. The lineated zones are bounded by large quasi-circular anomalies on the edge of possibly "continental" non magnetic zones. The results define a complex kinematic pattern of the opening of the Balearic Basin, in terms of plate tectonics.
\end{abstract}

\section{Introduction}

In this paper, we briefly report the results of a precise and homogeneous aeromagnetic survey covering the whole Balearic Basin $[1,2]$.

These results reveal the existence of zones of small amplitude lineated symmetrical magnetic anomalies which have not been detected by conventional surveys $[3,4]$. The survey was flown in two parts. The results of the northern part, flown at a level of $3600 \mathrm{~m}$ in 1966 , were previously published with a preliminary interpretation of them [1].

The results of the southern part are now available [2]. ** The survey was flown at $600 \mathrm{~m}$ with $10 \mathrm{~km}$ spacing between $\mathrm{N}-\mathrm{S}$ lines and $44 \mathrm{~km}$ spacing between $\mathrm{E}-\mathrm{W}$ traverses. The precision of the navigation is 10 meters in the $Z$-direction and 50 meters in the $x$ and $y$ directions. The absolute accuracy of the reduced values of the total intensity is $\mathbf{4}$ gammas over the whole survey.

* Contribution no. 130 of Département Scientifique of Centre Océanologique de Bretagne, 29200, Brest, France.

** Maps are sold by Bureau de Recherches Géologiques et Minières (Direction du Service National), B.P. 818, 45 Orleans-la-Source (France).
Fig. 1 shows a map of anomalies which combines the results of the two surveys. A highly precise downward continuation method, based on a $1 \mathrm{~km} \times 10 \mathrm{~km}$ network, was used to reduce the northern part to the $600 \mathrm{~m}$ level, except over Corsica. The agreement of the two maps in the overlapping region is better than 5 gammas in spite of the difference in time $(5 \mathrm{yr})$ and the calculations involved. The very close network spacing $(1 \mathrm{~km} \times 10 \mathrm{~km})$ used for the computation, compared to the much wider spacings previously used $(10 \mathrm{~km} \times 10 \mathrm{~km}$ in [1]), explains the greatly increased definition of the anomalies in the northern area, with respect to the previously published map. The details of the computations involved will be given in a later paper. This paper concentrates on a rapid publication of the main results, of which, the plate tectonic implications seem important to us.

\section{Description of the map}

An examination of the anomaly map reveals that, within a zone which is approximately outlined by the $2500 \mathrm{~m}$ isobath, magnetic anomalies appear to be li- 


\section{R. Bayer et al., Magnetic anomaly pattern in the western Mediterranean}

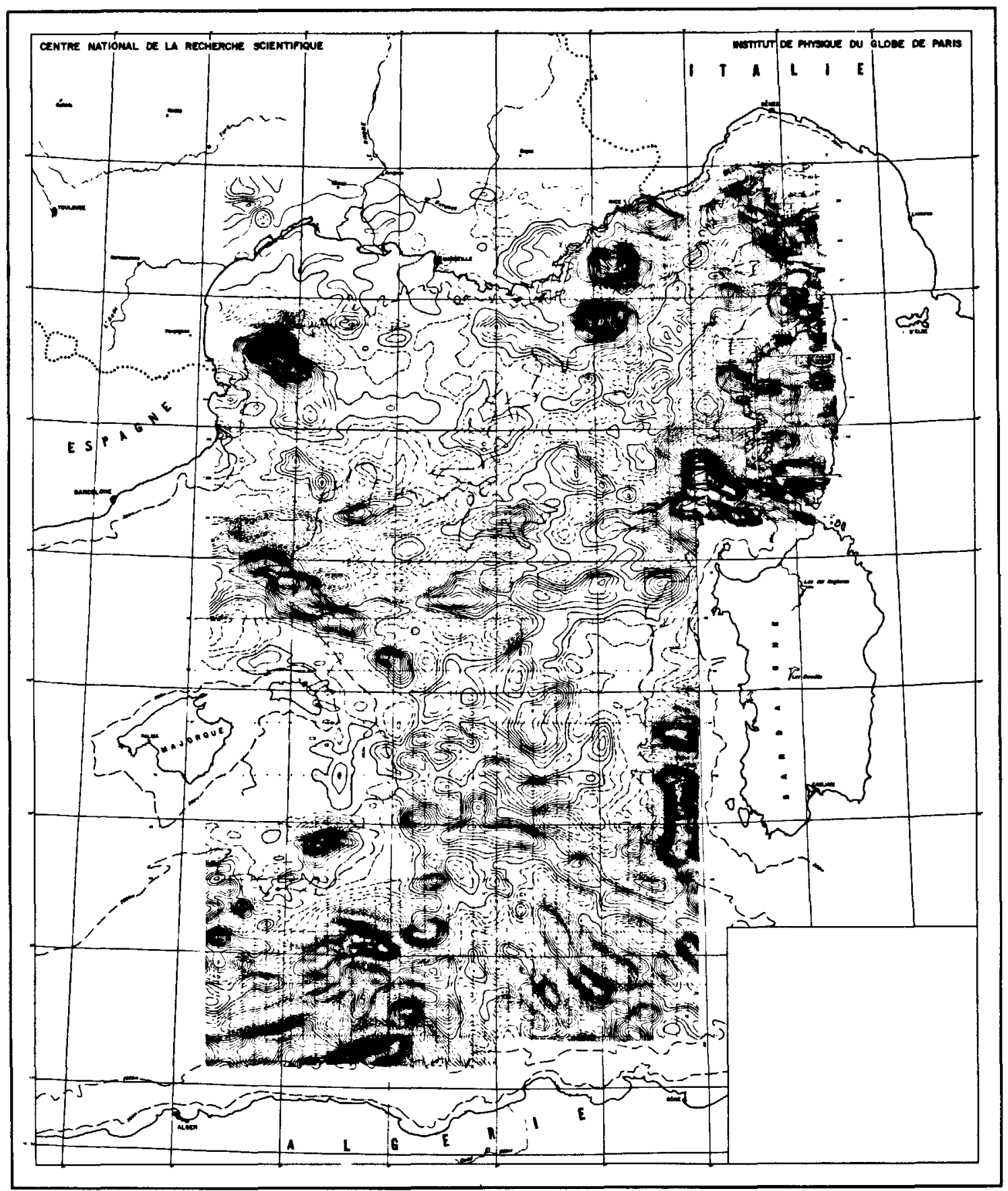

Fig. 1. Magnetic anomalies over the Balearic Basin. The part north of $40^{\circ} \mathrm{N}$ was flown at a $3000 \mathrm{~m}$ level in 1966 [1]. The resulting anomaly has been downward continued to a level of $600 \mathrm{~m}$, the part south of about $40.4^{\circ} \mathrm{N}$ was flown in 1971 at a $600 \mathrm{~m}$ level [2]. There is a band of overlap $40 \mathrm{~km}$ wide over which the agreement between the computed anomalies is better than 5 gammas everywhere. Contours are drawn every 10 gammas: continuous lines for positives and dashed lines for negatives. The regional field was obtained by a least squares second order fit. 


\section{$R$ Bayer et al., Magnetic anomaly pattern in the western Mediterranean}

near with a 100 gammas peak to peak amplitude. Three main zones can be recognized:

- A northern zone where the lineations are $E-W$ to SW-NE,

- A southeastern zone where the lineations are NW-SE,

- And a more confused southwestern zone, where the lineations appear to be mostly $E-W$.

These zones are surrounded either by magnetically smooth areas (especially off the western Sardinia and Balearic margins) or by large amplitude quasi-circular anomalies (especially off Provence, Corsica, Baleares and Southern Sardinia).

Le Borgne et al. [1] had shown that there is an equal distribution of normally and reversely magnetized material in the lineated portion of the northern area. We have verified the same property for the lineated portions of the southern part. This suggests that we are dealing with Vine and Matthews' type lineations [5].

Fig. 2 shows that the observed profiles in the southeastern area are roughly symmetrical with respect to anomaly $A_{\text {se }}$. In the northern area the anomalies $B_{\mathrm{n}}$ and $B_{\mathrm{n}}^{\prime}$ are grossly symmetrical with respect to $A_{\mathrm{n}}$. Although the symmetry is far from being perfect, as can be judged on the computed best fit distributions of magnetization, it is fair compared to many published Vine and Matthews profiles. Fig. 2 does not prove however that the southeastern and northern magnetic patterns are contemporaneous.
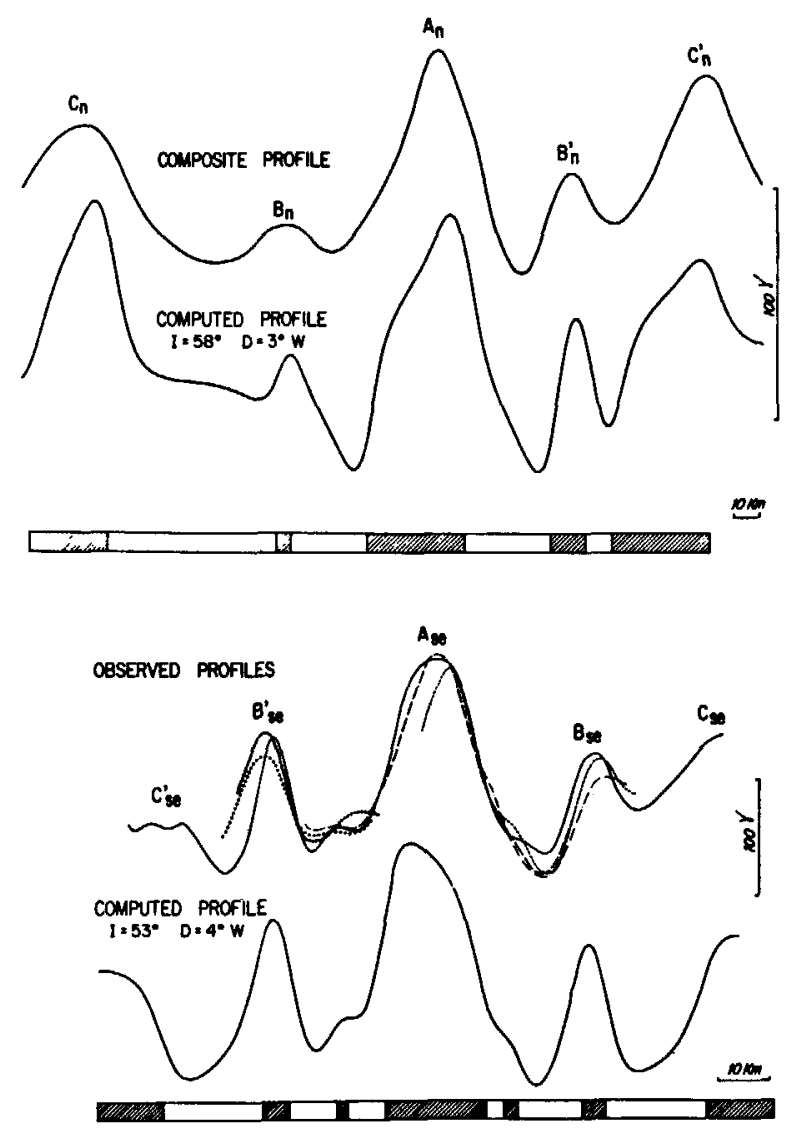

Fig. 2. Magnetic anomaly profiles across the northern (Sardinia Europe) and southeastern (Eastern Kabylia/Europe) lineated zones showing the gross symmetry with respect to anomalies $A_{\mathrm{n}}$ and $A_{\mathrm{se}}$. The northern profile is a composite profile obtained with portions of $\mathrm{N}-\mathrm{S}$ lines between small circles $3_{\mathrm{n}}$ and $8_{\mathrm{n}}$. The southern profile also is obtained with portions of $\mathrm{N}-\mathrm{S}$ lines between small circles $1_{\mathrm{se}}$ and $3_{\mathrm{se}}$. Best fit computed anomaly patterns confirm the existence of this gross symmetry (Inclination and declination of the magnetization vector of computed profiles are abbreviated by $I$ and $D$ ). 


\section{R. Bayer et al, Magnetic anomaly pattern in the western.Mediterranean}

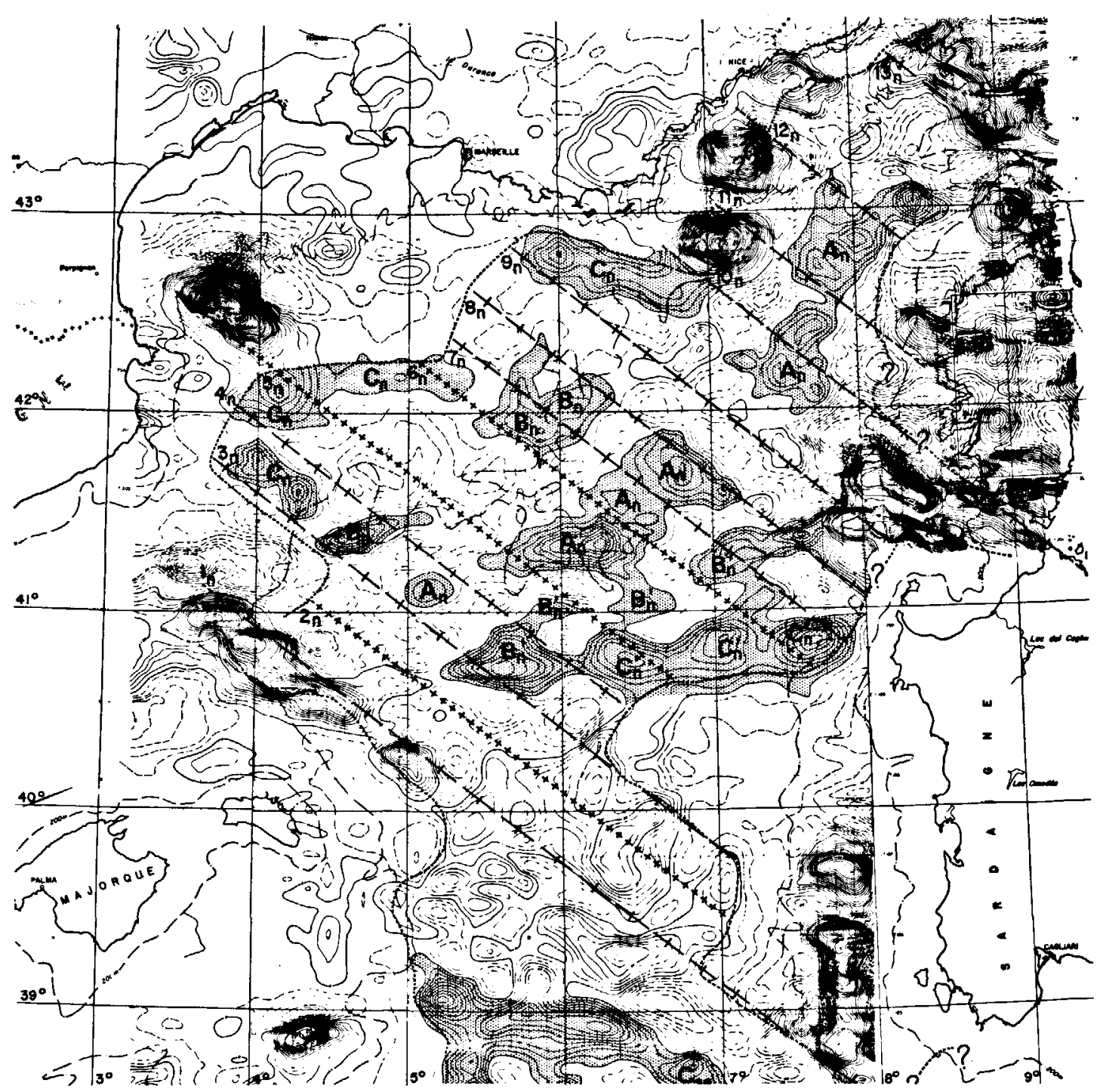

Fig. 3a. Map of magnetic anomalies of the northern part: patterns of linear magnetic anomaly are identified by capital letters. Theoretical small circles about the Corsica-Sardinia/Europe pole of relative rotation $\left(56^{\circ} 5 \mathrm{~N}, 105^{\circ} \mathrm{E}\right)$ are also shown. The edge of the zones of linear magnetic anomalies are outlined, thus defining the "predrift" areas.

On the basis of the profiles of fig. 2, we have identified the anomalies on figs. $3 a, b$ and thus define more precisely the exact limits of the symmetrical pattern of lineated anomalies. The identification is not always sure, especially between Corsica and Europe, but the solution adopted seems probable to us. The identification of the anomaly patterns has enabled us to identify fracture zones along which the anomalies are offset.
The most obvious fracture zones are dashed in figs. 3a, $\mathrm{b}$ while the less obvious ones are dotted. We have not been able to identify clearly the age of the anomalies but the best fit is obtained if anomalies $A_{\mathrm{se}}$ to $C_{\mathrm{se}}$ correspond to the Upper Lower Miocene. However, the number of reversals is too small to give a good correlation. 


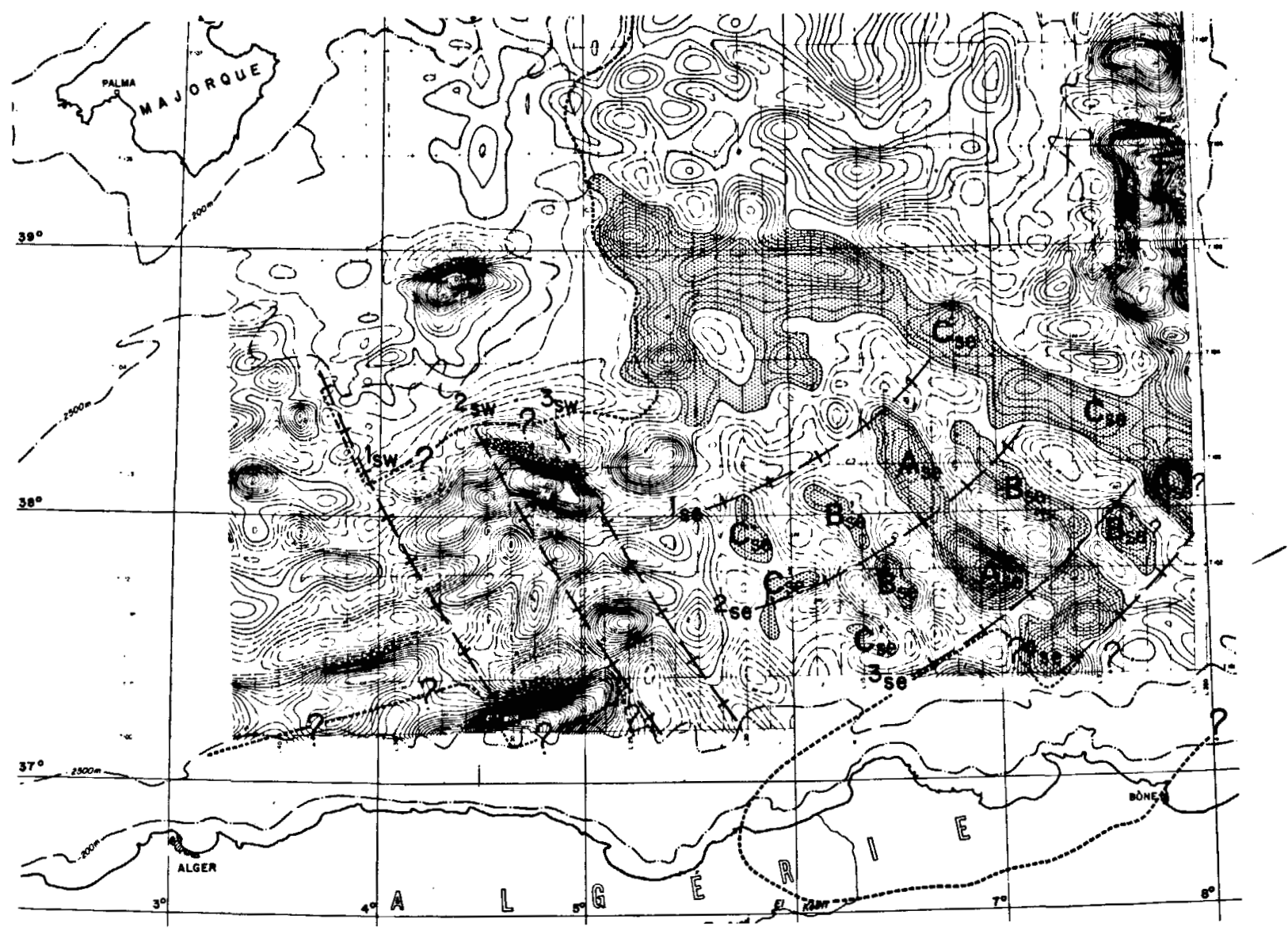

Fig. 3b. Same as fig. 3a, southern part. Theoretical small circles about the Eastern Kabylia/Sardinia pole $\left(39.8^{\circ} \mathrm{N}, 4.9^{\circ} \mathrm{E}\right)$ and the western Kabylia/Baleares pole $\left(41.3^{\circ}, 13^{\circ} \mathrm{E}\right)$ are also shown.

Fig. 3 suggests that the three magnetically lineated domains were respectively created by the relative motion of Corsica and Sardinia with respect to Europe, Eastern Kabylia with respect to Sardinia and Western Kabylia with respect to the Baleares.

The system of fractures between Sardinia-Corsica and Europe is well defined, in particular fracture zones $1_{n}, 3_{n}, 8_{n}$ and $10_{n}$. Fracture $1_{n}$ seems to mark the southern limit of the drift of Sardinia. Fracture $10_{n}$ probably marks the relative motion between Corsica and Sardinia: the straits of Bonifacio corresponding to a transform fault. Within the southeastern domain, the lineated anomalies define a triangular zone with at least three clearly defined fracture zones. Fracture zone $4_{\mathrm{se}}$ is poorly defined and the anomalies between $3_{\mathrm{se}}$ and $4_{\text {se }}$ cannot be properly recognized as the northeastern end is missing.

The southwestern part is the least well defined of the three. No clear pattern of anomalies could be recognized. However, three fracture zones appear to be well defined, especially $1_{s w}$. As the pattern of anomalies has not been identified, the limits of the lineated zone are somewhat arbitrary and might be moved, especially to the south. A third aeromagnetic survey, which will be flown to the west in 1973, may help to solve this problem. However the smooth zone south of the Baleares is well defined and is only disturbed by a large anomaly, which is clearly due to an isolated positively magnetized body. 


\section{R. Bayer et al., Magnetic anomaly pattern in the western Mediterranean}

The smooth zone west of Sardinia extends quite far to the west and is only disturbed by a long N-S very large positive anomaly parallel to the Sardinia coast which cannot be explained simply in terms of a unique body magnetized along the present earth's field direction. The group of very large NW-SE anomalies north of the Baleares is known to correspond to an igneous edge along fracture zone $1_{n}[1,6]$. The large anomalies in the Gulf of Lion is due to a unique positively magnetized body, apparently lying along the prolongation of fracture zone $5_{n}$. The two large anomalies off Provence probably correspond to igneous intrusions but little is known about their actual structure and the edge of the non lineated zone is poorly defined; similarly the edge of the zone off Corsica is poorly defined. The most northern NW-SE large amplitude anomaly, which lies along fracture zone $13_{n}$ also corresponds to a well defined positively magnetized body.

\section{Pre-Balearic Basin reconstruction}

Having recognized the presence of roughly symmetrical magnetic lineations, offset by fracture zones, it is reasonable to consider that they were produced by sea floor spreading. Thus it is possible to compute precisely the relative kinematics of opening of the Balearic Basin in terms of rigid plates. To do that, we first compute the eulerian poles of rotation [7] such that fracture zones are small circles about them. Three poles were computed corresponding to the three zones previously defined. The pole which is the best defined, corresponding to the southeastern zone is close to Minorca. The pole relative to fracture zones $1_{n}$ to $13 n$ is situated about $60^{\circ}$ away in Siberia. The southwestern pole is very poorly defined and is only a convenient way to describe motion along the general trend of fracture zones $1_{\text {sw }}$ to $3_{\mathrm{sw}}$. We then obtain the finite angles necessary to eliminate the lineated portions by moving the "smooth" zones on each side together along the fracture zones. The angle is well defined for Sardinia with respect to Europe and for Eastern Kabylia with respect to Sardinia. It is poorly defined for Corsica with respect to Europe and Western Kabylia with respect to the Baleares.

Fig. 4 was obtained by using these parameters to first eliminate the southeastern and southwestern por- tions, then the northern portion. The southern limits of the two Kabylias were taken at the limit of the crystalophilian internal massifs and the external zones [8]. No discussion of the geological implications of this pattern will be made here. The only aim is to provide a correct reconstruction of different pieces of this geological puzzle prior to the drift.

Note that this pattern implies that the total angular cenozoic rotations of Sardinia and Corsica are very small, much less than what has been proposed on the basis of paleomagnetic results $[9,10]$. However, most scientists have ignored the fact that the rotation of the Iberian Peninsula during the Mesozoic must have been accompanied by the rotation of Corsica and Sardinia. Thus the post hercynian rotations of Corsica and Sardinia should be the composition of the mesozoic rotation of Iberia and the cenozoic rotation of Corsica and Sardinia. Thus our data are compatible with a post hercynian $30^{\circ}$ rotation of Corsica but not with a $40^{\circ}$ post oligocene rotation of Sardinia [10].

Auzende et al. [6] previously arrived, using in part different criteria, at a kinematic pattern which is similar to the one we proposed for the motion of Sardinia and Corsica with respect to Europe but differs for the southeastern and southwestern portions. Note that the eastern limits chosen for the Sardinia and Corsica plates are arbitrary. A more complete reconstruction, which includes the Tyrrhenian sea opening is in preparation.

\section{Schematic model of opening}

The rather compact reassembly of fig. 4 probably corresponds to the Early to Middle Oligocene time $[6,12]$. It is probable that the opening occurred while an oceanic zone, situated between the Kabylia's internal zones and the African platform, was being closed. Thus, the opening of the Balearic Basin is analogous to the opening behind consuming plate boundaries of the marginal basins of Karig [13].

The kinematic pattern (fig. 5) suggests that the Sardinia block first detached itself from Europe with the Eastern Kabylia block attached. A strike-slip movement of about $150 \mathrm{~km}$ was occurring along the straits of Bonifacio between Corsica and Sardinia. There is a slight disagreement in trend between the straits of Bonifacio and fracture zone $10_{n}$, which re- 


\section{$R$ Bayer at al., Magnetic anomaly pattern in the western Mediterranean}

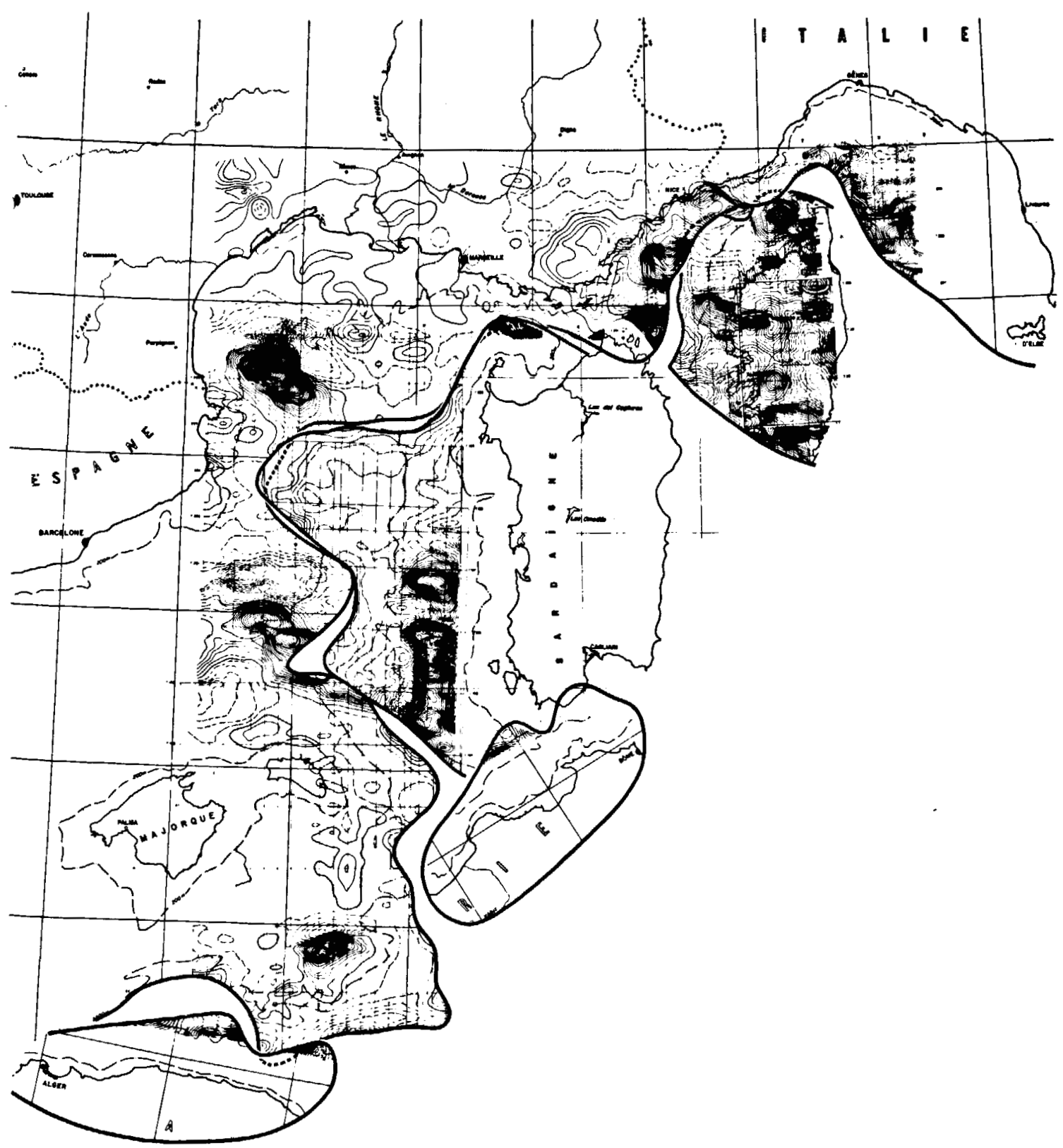

Fig. 4. Predrift reconstruction before the creation of the Balearic Basin obtained by eliminating the areas covered by linear anomalies. The poles used are those given in the caption of fig. 1 . The angles of relative rotation are $-1.09^{\circ}$ for Corsica/Europe, $+34^{\circ}$ for Eastern Kabylia/Sardinia, and $-8.5^{\circ}$ for Western Kabylia/Baleares.

sults in a $5 \mathrm{~km}$ overlap of Sardinia over Corsica. However, this trend may not be defined precisely enough or there may have been some distension after the strikeslip motion occurred. When Sardinia became docked in its present position with respect to Corsica, the last part of the common Corsica Sardinia opening proceeded, thus creating anomaly $A_{\mathrm{n}}$ and the adjacent negative anomalies. The next opening then seems to 


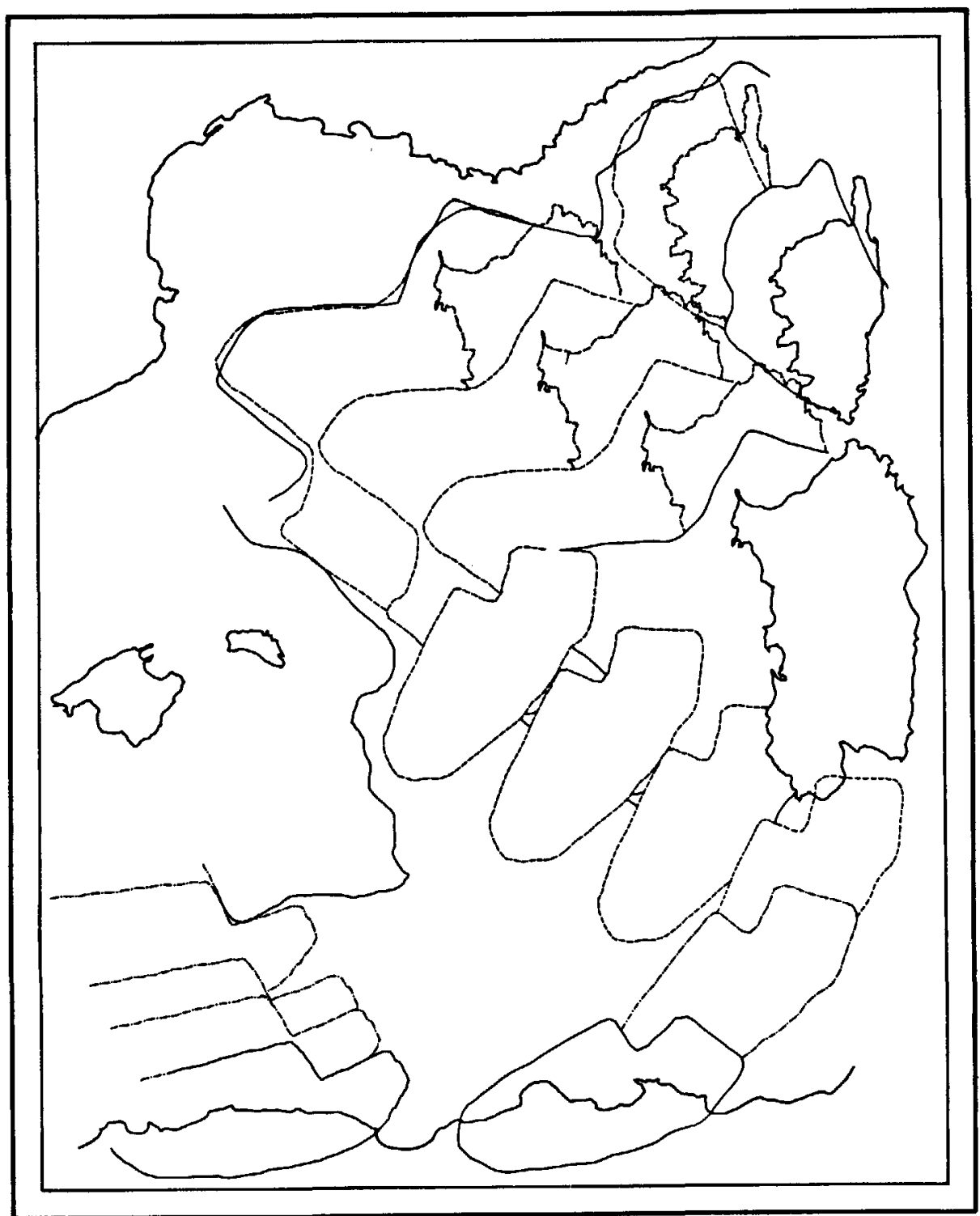

Fig. 5. Schematic model of opening using the parameters of figs. 1 and $3 a, b$.

be the separation of the eastern Kabylia block and Sardinia. The western Kabylia block presumably separated later from the Baleares, so that a surface equivalent to the surface created by the southeastern opening could be absorbed south of the Baleares and southwestern Kabylia blocks. It is clear however that this tentative model of opening needs to be confirmed by a proper dating of the anomalies.

\section{Conclusions}

We have shown that the floor of the Balearic Basin is covered by small amplitude Vine and Matthews' type lineations. This has led us to infer a predrift reconstruction of the blocks surrounding the Balearic Basin. This reconstruction disagrees with all previously published reconstructions and with the conclusions 


\section{R. Bayer et al., Magnetic anomaly pattern in the western Mediserranedn}

obtained from paleomagnetic work for Sardinia. The very complex kinematic pattern could not have been guessed without the magnetic data. Yet, the anomalies clearly suggest that the openings occurred in terms of rigid plates. Obvious geological tests of this reconstruction can be made by geological comparisons of pre-Oligocene formations between the northern tip of Sardinia, Corsica and Provence and between Eastern Kabylia and Southern Sardinia. Also, the transform fault nature of the Straits of Bonifacio could be tested. However, care should be taken to allow for the rotation of the Iberian Peninsula during the Mesozoic when relating pre-Mesozoic structures [11].

\section{Acknowledgments}

E. Le Borgne was in charge of the program of overall aeromagnetic survey and gave advice and help at every stage. The discussions with J.M. Auzende, J. Bonnin and J.L Olivet were helpful.

\section{References}

[1] E. Le Borgne, J.L. Le Mouel and X. Le Pichon, Aeromagnetic survey of Southwestern Europe, Earth Planet. Sci. Letters 12 (1971) 287-299.

[2] E. Le Borgne, R. Bayer and J.L. Le Mouel, La cartographie magnétique de la partie sud du bassin Algéro-Provençal, Compt. Rend. 274 (1972) 1291-1294.
[3] P.R. Vogt, R.H. Higgs and C.L..Johnson, Hypotheses on the origin of the Mediterranean basin: Magnetic data, J. Geophys. Res. 76 (1971) 3207-3228.

[4] X Lt Pichon, Discussion of a paper by P.R. Vogt, R.H. Higgs land G.J. Johnson, "Hypotheses on the origin of the Madditerranean basin: Magnetic data", J. Geophys. Res. जf (1972) 391-393.

[5] F.J. Vine and D.H. Matthews, Magnetic anomalies over oceanic ridges, Nature 199 (1963) 947-949.

[6] J.M. Auzende, J. Bonnin and J.L. Olivet, Hypotheses on the origin of the western Mediterranean Basin, J. Geol. Soc. (London) in press.

[7] X. Le Pichon, J. Francheteau and J. Bonnin, Plates tectonics (Elsevier) in press.

[8] Durand-Delga, Mise au point sur la structure de NE de la Berberie, Pub. Serv. Geol. Algérie 39 (1969) 89-131.

[9] A.E.M. Nairn and M. Westphal, Possible implications of the paleomagnetic study of late paleozoic igneous rocks of northern Corsica, Paleography, Paleoclimatology, $\mathrm{Pa}$ leocology 5 (1968) 179.

[10] J.D. Zijderveld, K.A. De Jong and R. van der Voo, Rotation of Sardinia: Paleomagnetic Evidence from Permian Rocks, Nature 226 (1970) 933.

[11] X. Le Pichon, J. Bonnin, J. Francheteau and J.C. Sibuet, Une hypothese d'evolu tion tectonique du golfe de Gascogne - Histoire structurale du golfe de Gascogne, Vol. 2 (Technip, Paris, 1971) p. VI/11/10 - VI/11/44.

[12] X. Le Pichon, G. Pautot, J.M. Auzende and J.L. Olivet, La Méditerranée occidentale depuis l'Oligocène Schéma d'evolution, Earth Planet. Sci. Letters 13 (1971) 145-152.

[13] D.E. Karig, Origin and development of marginal basins in the western Pacific, J. Geophys. Res. 76 (1971) 25422561. 